\title{
Modulating the concentrations of reactive oxygen and nitrogen species and oxygen in water with helium and argon gas and plasma jets
}

Kotaro Ogawa, Jun-Seok Oh, Nishtha Gaur, Sung-Ha Hong, Hirofumi Kurita, Akira Mizuno, Akimitsu Hatta, Robert D. Short, Masafumi Ito, Endre J. Szili

\begin{tabular}{|c|l|}
\hline Citation & Japanese Journal of Applied Physics, 58 (SA); SAAB01 \\
\hline Issue Date & $2018-11-23$ \\
\hline Type & Journal Article \\
\hline Textversion & Author \\
\hline \multirow{3}{*}{ Rights } & $\begin{array}{l}\text { C } 2018 \text { The Japan Society of Applied Physics. } \\
\text { This is the accepted manuscript version. Please cite only the published version. } \\
\text { The article has been published in final form at https://doi.org/10.7567/1347-4065/aaea6b }\end{array}$ \\
\hline DOI & $10.7567 / 1347-4065 /$ aaea6b \\
\hline
\end{tabular}

\author{
Self-Archiving by Author(s) \\ Placed on: Osaka City University
}

Kotaro Ogawa et al. (2018). Modulating the concentrations of reactive oxygen and nitrogen species and oxygen in water with helium and argon gas and plasma jets. Japanese Journal of Applied Physics. 58, SAAB01. https://doi.org/10.7567/1347-4065/aaea6b 


\section{Modulating the concentrations of reactive oxygen and nitrogen species and oxygen in water with helium and argon gas and plasma jets}

Kotaro Ogawa ${ }^{1}$, Jun-Seok Oh ${ }^{2,3 *}$, Nishtha Gaur ${ }^{4,5}$, Sung-Ha Hong ${ }^{4}$, Hirofumi Kurita ${ }^{6}$, Akira Mizuno $^{6}$, Akimitsu Hatta ${ }^{1,7}$, Robert D. Short ${ }^{4,8}$, Masafumi Ito $^{2}$, and Endre J. Szili ${ }^{4 *}$

1 Department of Electronic and Photonic Systems Engineering, Kochi University of Technology, Kami, Kochi 782-8502, Japan

${ }^{2}$ Department of Electrical and Electronic Engineering, Meijo University, Nagoya 468-8502, Japan

${ }^{3}$ Department of Physical Electronics and Informatics, Osaka City University, Osaka, 5588585 Japan

${ }^{4}$ Future Industries Institute, University of South Australia, Adelaide, SA 5095 Australia

${ }^{5}$ Wound Management Innovation Cooperative Research Centre, Australia

${ }^{6}$ Department of Environmental and Life Sciences, Toyohashi University of Technology, Toyohashi, Aichi 441-8580, Japan

${ }^{7}$ Center for Nanotechnology, Research Institute of Kochi University of Technology, Kami, Kochi 782-8502, Japan

${ }^{8}$ Materials Science Institute, The University of Lancaster, City of Lancaster LA1 4YW, UK

*E-mail: jsoh@osaka-cu.ac.jp; endre.szili@unisa.edu.au

Herein, we employed UV-Vis spectroscopy to monitor real-time changes in the oxygen tension and concentration of reactive oxygen and nitrogen species (RONS) in deionized (DI) water during treatments with helium (He) and argon (Ar) gas and plasma jets. He and Ar gas jets are both shown to de-oxygenate DI water with $\mathrm{He}$ being more efficient than Ar, whilst the plasma jets deliver and regulate the concentrations of hydrogen peroxide $\left(\mathrm{H}_{2} \mathrm{O}_{2}\right)$, nitrite $\left(\mathrm{NO}_{2}{ }^{-}\right)$and nitrate $\left(\mathrm{NO}_{3}{ }^{-}\right)$in deionized (DI) water. The $\mathrm{H}_{2} \mathrm{O}_{2}$ and $\mathrm{NO}_{3}{ }^{-}$production efficiency varied between $\mathrm{He}$ 
and Ar plasma jets, but was similar for $\mathrm{NO}_{2}{ }^{-}$. Whilst DI water fully equilibrated with ambient air prior to treatment, was de-oxygenated by both plasma jets, when the DI water was first de-oxygenated by an inert gas jet treatment, both plasma jets were found to be capable of oxygenating the DI water. These insights were then used to show how different combinations of plasma jet and inert gas jet treatments can be used to modulate $\mathrm{O}_{2}$ tension and RONS chemistry. Finally, potential further improvements to improve control in the use of plasma jets in regulating $\mathrm{O}_{2}$ and RONS are discussed. 


\section{Introduction}

Cold atmospheric helium (He) or argon (Ar) plasma jets (herein referred to as plasma jets) impinging on air, generate a cocktail of reactive oxygen species (ROS) and reactive nitrogen species (RNS), or collectively RONS. ${ }^{1-5)}$ When these plasma jets are aimed at an aqueous liquid target, the RONS in the effluent of the flowing gas can dissolve into the liquid phase and from there participate in chemical reactions; e.g. protein oxidation ${ }^{6)}$ or redox reactions. ${ }^{7)}$ It was also shown that the inert gas of plasma jets can deoxygenate DI water. ${ }^{8,9)}$ In the case of applications to biological media, RONS species could potentially interact with biological molecules and/or components of the cells. ${ }^{7)}$ And cell fate is known to be sensitive to aqueous oxygen $\left[\mathrm{O}_{2}(\mathrm{aq})\right]$ tension. ${ }^{8,10)}$ We also note that there are many different designs of plasma sources, ${ }^{11)}$ which will produce different RONS chemistry in aqueous liquids. In addition, the composition of the surrounding air such as oxygen and nitrogen content ${ }^{12)}$ and humidity, ${ }^{13)}$ as well as the initial liquid chemistry, ${ }^{14)}$ will significantly influence the resultant RONS chemistry in the plasma jet-treated liquid. Another important parameter is whether or not the plasma jet is in contact with the liquid surface, which can also significantly influence the resultant RONS chemistry in the liquid. ${ }^{15)}$

$\mathrm{He}$ and Ar are commonly chosen as feed gases because plasma jets formed from these gases can be operated with relatively low breakdown thresholds and sustainable voltages, ${ }^{16)}$ and because of the relative affordability of He and Ar gases. In order to achieve control, efficiency, and predictability over processing outcomes, it is important to understand the exact nature of $\mathrm{He}$ and Ar plasma jets/water interactions and what process variables most influence these. This is particularly important where He and Ar plasma jets exhibit different discharge characteristics ${ }^{17-20)}$ which could potentially influence the delivery of RONS into the target liquid. In order to measure the real-time changes in the concentrations of $\mathrm{O}_{2}(\mathrm{aq})$ and RONS species in DI water during the plasma jet treatment, we developed a UV-Vis spectroscopy (UV-Vis) method. ${ }^{9,21-25)}$ We have shown in a previous study, UV-Vis spectroscopy can be used to accurately determine the concentrations of $\mathrm{H}_{2} \mathrm{O}_{2}, \mathrm{NO}_{2}{ }^{-}$and $\mathrm{NO}_{3}{ }^{-}$ in reference solutions, with mixed concentrations of these molecules, even with varying $\mathrm{O}_{2}$ (aq) tension levels. $\left.{ }^{9}\right)$ Two important observations from the initial and follow-up studies were that (1) the choice of He or Ar process gas influences the resultant RONS chemistry generated by the plasma jet, ${ }^{9)}$ and (2) both He and Ar plasma jets de-oxygenate DI water. ${ }^{8,9}$, 
23, 24, 26) De-oxygenation of the DI water with both plasma jets was attributed to the inert $\mathrm{He}$ or Ar gas in the partially ionized plasma jet, purging $\mathrm{O}_{2}(\mathrm{aq})$ out of the DI water. The importance of considering oxidation, oxygenation and de-oxygenation effects on biological cells from plasma jets was discussed in a recent study, where it was shown how each effect contributed towards the regulation of the viability of skin cells cultured in vitro. ${ }^{8}$

In this study, using the UV-Vis spectroscopy, He and Ar gases and plasma jets are first compared and then it is shown how combinations of gas/plasma jet treatments can regulate the concentrations of hydrogen peroxide $\left(\mathrm{H}_{2} \mathrm{O}_{2}\right)$, nitrite $\left(\mathrm{NO}_{2}{ }^{-}\right)$and nitrate $\left(\mathrm{NO}_{3}{ }^{-}\right)$, which are the main longer-lived RONS generated by plasma in DI water, ${ }^{27-31)}$ as well as $\mathrm{O}_{2}(\mathrm{aq})$. These new data are discussed in the context of how to exploit $\mathrm{He}$ and Ar plasma jets more effectively and efficiently in the regulation of $\mathrm{O}_{2}(\mathrm{aq})$ tension and RONS chemistry in aqueous solutions.

\section{Experimental methods}

\subsection{Plasma jet}

The plasma jet configuration has been described in detail elsewhere. ${ }^{9,23-25,32)}$ Briefly, the plasma jet assembly consisted of a $150 \mathrm{~mm}$ long, $4 \mathrm{~mm}$ inner diameter glass tube that was tapered to $650 \mu \mathrm{m}$ at the nozzle. Power was supplied to a single $15 \mathrm{~mm}$ long external ring copper electrode wound onto the glass tube at a distance of $40 \mathrm{~mm}$ from the nozzle. The plasma jet assembly was used in a single electrode configuration (with no second grounded electrode). The flow rate of He or Ar through the glass tube was fixed at 0.5 standard litres per minute (slpm). During He or Ar plasma jet operation (for the free stream plasma jet) the velocity of the gas flow in both cases was $25 \mathrm{~m} / \mathrm{s}$, and the Reynolds number was calculated to be 148 and 1361, respectively (see supporting information for calculation, available online at stacks.iop.org/JJAP/58/SAAB01/mmedia). According to these Reynolds numbers, both $\mathrm{He}$ and Ar plasma jets were expected to operate with laminar gas flow. ${ }^{33)}$ However, the Ar plasma jet appeared more filamentary, which would have generated additional gas turbulence and mixing of the plasma effluent with the ambient air. With the plasma off, the neutral gas velocity was expected to be $10-30 \%$ lower. ${ }^{34)}$ A high voltage sinusoidal wave pulse of $10 \mathrm{kV}_{\mathrm{p}-\mathrm{p}}$ (peak-to-peak) at $30 \mathrm{kHz}$ was applied to the external electrode with a PVM500 power supply (Information Unlimited: New Hampshire, USA). A $5 \mathrm{~mm}$ thick 
polytetrafluoroethylene (PTFE) housing was used to shield the high voltage electrode for safety. Under the parameters described above, the length of the free stream plasma jet, as seen with the unaided eye and measured with a ruler, was $\approx 7 \mathrm{~mm}$ and $\approx 5 \mathrm{~mm}$ for the $\mathrm{He}$ and Ar plasma jet, respectively. Voltage and current waveforms of the plasma jets were measured with a high voltage probe (Tektronix, model \# P6015A) and a current monitor (Pearson, model \# 2877) respectively.

\subsection{Plasma-activated water}

Deionized water (DI water) $\left(18.2 \mathrm{M} \Omega \cdot \mathrm{cm}\right.$ at $\left.25^{\circ} \mathrm{C}\right)$ was obtained from a Millipore Direct-Q 3UV system. Approximately $500 \mathrm{~mL}$ of DI water was stored in a container in ambient atmosphere for one day before experiments. This storage procedure enabled the concentrations of dissolved gases within the DI water and the temperature to equilibrate with the air, which ensured that the concentrations of dissolved gases were constant between experiments.

\subsection{UV-vis spectroscopy}

A conventional double-beam UV-Vis spectrophotometer (U-3900, Hitachi) was used to measure the UV absorbance of $4.1 \mathrm{~mL}$ DI water inside the quartz cuvette with a standard optical path of $10 \mathrm{~mm}$. The plasma jet assembly, including an $x-y-z$ positioning stage, was mounted on the spectrophotometer. The nozzle of the plasma jet assembly was held $5 \mathrm{~mm}$ from the top of the DI water (Scheme and photograph in Fig. 1). The impact of the gas flow during plasma jet or neutral gas flow treatments created a slight indentation on the surface of the DI water, which increased the actual treatment distance by a negligible amount of $<1$ $\mathrm{mm}$. In addition, evaporation of DI water during the various treatments can further decrease the water level. The maximum amount of DI water that was evaporated for any of the experiments in this study was $13.6 \%$ - this was calculated for DI water treated with the plasma jet for $60 \mathrm{~min}$, which corresponded to an approximate $4 \mathrm{~mm}$ decrease in the DI water level. The typical plasma jet treatment times of $15 \mathrm{~min}$ in this study resulted in a decrease in the water level of $1 \mathrm{~mm}$. According to Henry's Law the water temperature will change the solubility of gases, which can influence the plasma jet delivery of RONS in the DI water. ${ }^{35}$, 36) The influence of temperature is discussed later. 
The plasma jet was aimed downward onto the DI water and real-time changes in the UV absorption profile were recorded during plasma jet treatment. The detection position was 35 $\mathrm{mm}$ below the water surface level (Fig. 1), which we estimate is equivalent to a 1 min delay in receiving the absorption signal (i.e. the time taken for the RONS to diffuse through the water to the detection area). As seen with the unaided eye, the He plasma jet contacted the DI water up to 10 min of treatment, but lost contact between (10-15 min); whereas the shorter length Ar plasma jet never contacted the water surface. The exact same operational parameters were also employed for the He and Ar gas treatments with the only difference being no applied voltage. The UV absorbance was used to calculate the concentrations of $\mathrm{H}_{2} \mathrm{O}_{2}, \mathrm{NO}_{2}^{-}, \mathrm{NO}_{3}{ }^{-}$and $\mathrm{O}_{2}(\mathrm{aq})$, according to an established curve-fitting routine using reference spectra of known concentrations of $\mathrm{H}_{2} \mathrm{O}_{2}$, sodium nitrite $\left(\mathrm{NaNO}_{2}\right)$ and nitric acid $\left(\mathrm{HNO}_{3}\right)$ solutions. ${ }^{9)}$ A diagrammatical representation of the complete experimental set-up is shown in Fig. 1.

The $\mathrm{pH}$ and temperature of the DI water, treated under the same experimental parameters used in UV-Vis spectroscopy, was measured with a commercially available $\mathrm{pH} /$ temperature meter (Model D-71, Horiba).

All data points are representative of three replicate experiments $(n=3)$ and error bars are \pm standard deviations of the replicates.

\section{Results and discussion}

\subsection{Discharge current and voltage}

The applied voltage waveforms, discharge currents $\left(I_{\text {Dis }}\right)$ and input powers (a.k.a. discharge power) for the He and Ar plasma jets are shown in Fig. 2. The sinusoidal waveforms were identical between the He and Ar plasma discharges. The peak $I_{\text {Dis }}$ and input powers were higher for Ar compared to He. But the averaged input power over one discharge period of $33 \mu \mathrm{s}$ was similar between $\mathrm{He}$ and Ar at $\sim 0.47 \mathrm{~W}$. Therefore, the average input energies for He and Ar, calculated after 15 min of operation, which was the usual treatment time investigated in this study, were $351 \mathrm{~J}$ and $354 \mathrm{~J}$ for He and Ar, respectively. However, the input power can vary between He and Ar plasma jets depending on the experimental parameters, as noted in a previous publication. ${ }^{9)}$ Because the input power was similar between $\mathrm{He}$ and Ar plasma jets in this study, the effect of input power on any differences in 
RONS delivery can be discounted.

\subsection{UV-vis}

Employing the set-up shown in Fig. 1, UV-Vis spectroscopy was utilized to quantify the concentrations of RONS in the DI water in real-time employing different combinations of $\mathrm{He}$ or Ar gas and plasma jet treatments. In Fig. 3, DI water was first treated with either a He or Ar plasma jet for 15 min before the applied voltage and gas flow were extinguished. UVVis measurements were first taken for 15 min during the plasma jet treatments and for 45 min after the plasma and gas flow were extinguished. The results are shown in terms of the total UV absorbance $\left(A_{\mathrm{T}}\right.$, sum of absorption signal intensity in the scanning wavelength range between 190 and $340 \mathrm{~nm}$ ) and total concentrations of $\mathrm{H}_{2} \mathrm{O}_{2}, \mathrm{NO}_{2}{ }^{-}, \mathrm{NO}_{3}{ }^{-}$and $\mathrm{O}_{2}(\mathrm{aq})$ in the DI water [where $A_{\mathrm{T}}$ is accounted for by these RONS and $\mathrm{O}_{2}(\mathrm{aq})$ ]. For both $\mathrm{Ar}$ and $\mathrm{He}$, it can be seen that there was an almost immediate and monotonic increase in the $A_{\mathrm{T}}, \mathrm{H}_{2} \mathrm{O}_{2}$, $\mathrm{NO}_{2}{ }^{-}$and $\mathrm{NO}_{3}{ }^{-}$, indicating fast solvation of these RONS into the DI water during plasma jet treatment. The Ar plasma jet delivered a higher concentration of $\mathrm{H}_{2} \mathrm{O}_{2}$, whereas the $\mathrm{He}$ plasma jet delivered more $\mathrm{NO}_{3}{ }^{-}$, and a similar concentration of $\mathrm{NO}_{2}{ }^{-}$was delivered by both plasma jets. Both plasma jets reduced the $\mathrm{O}_{2}(\mathrm{aq})$ concentration in the DI water to a similar level, although the recovery in $\mathrm{O}_{2}(\mathrm{aq})$ (post plasma jet treatment) did vary. De-oxygenation of the DI water is attributed to the inert gas component of the partially ionized plasma jets, purging $\mathrm{O}_{2}(\mathrm{aq})$ out of the DI water as previously discussed. ${ }^{8,9)}$ The differences observed (here) in the delivery of RONS between He and Ar plasma jets do not corroborate previously published data. ${ }^{9)}$ This discrepancy is because in terms of differences in the plasma operating parameters. When the plasma and gas flows were extinguished it can be seen that the concentration of RONS remained constant, simply because the plasma jets were no longer delivering RONS; but at the same time the $\mathrm{O}_{2}(\mathrm{aq})$ concentration in the DI water began to increase. This increase in $\mathrm{O}_{2}(\mathrm{aq})$ results from $\mathrm{O}_{2}$ from the ambient air, solvating back into the DI water.

The ability of the plasma jets to deliver stable RONS (from the reactive gas component) and simultaneously to deoxygenate (from the inert gas component) could potentially be exploited to modulate the ratio of RONS/O for both $\mathrm{He}$ and $\mathrm{Ar}$ in the next experiment, where DI water was first treated for 15 min with 
either an Ar or He plasma jet before the applied voltage (i.e. plasma) was extinguished and the (respective) inert gas jet was applied for a further $45 \mathrm{~min}$. The results are shown in Fig. 4. The trends in the delivery of RONS and de-oxygenation are similar to those described from Fig. 3 for the first $15 \mathrm{~min}$ of plasma jet treatment. When the plasma jets were extinguished and gas jets left on, the concentrations of RONS once again stabilized in the DI water because the plasma jets were no longer delivering RONS (consistent with Fig. 3). However, in both cases the $\mathrm{O}_{2}(\mathrm{aq})$ concentration continued to decrease and at rates that exceeded those for when the Ar and He plasma jets were ignited as expected from the literature. ${ }^{8,9,37)}$ Nearly all of the $\mathrm{O}_{2}(\mathrm{aq})$ was removed from the DI water at the $\sim 30$ min timepoint by the He gas jet. At the $\sim 25$ min time-point the Ar gas jet had reduced the $\mathrm{O}_{2}(\mathrm{aq})$ concentration to $\sim 2-3 \mathrm{mgL}^{-1}$; this was the lowest $\mathrm{O}_{2}$ (aq) concentration that could be achieved with the Ar gas jet and pro-longed treatment did not further reduce the $\mathrm{O}_{2}(\mathrm{aq})$. Occasionally, the RONS concentrations continued to increase during inert gas treatments for DI water initially treated with the plasma jets (e.g. see $\mathrm{H}_{2} \mathrm{O}_{2}$ graph in Fig. 4).

It should be noted that the RONS and $\mathrm{O}_{2}(\mathrm{aq})$ concentrations did not always precisely match between experiments. This is presumably due to experimental variation or small errors in the automated curve-fitting routine of the UV-Vis data as noted in a previous publication. ${ }^{9}$ ) These errors might also arise from the highly complex physicochemical processes occurring particularly near the surface of the DI water during plasma jet treatments, which lead to generation of further RONS not accounted for in this study ${ }^{38)}$ - in this study we focus only on the major longer-lived RONS generated by atmospheric plasma in water. In addition, post-plasma jet treatment we observed that the $\mathrm{H}_{2} \mathrm{O}_{2}$ concentration generally continued to slightly increase (see Figs. 3-5), whereas the concentrations of $\mathrm{NO}_{2}{ }^{-}$or $\mathrm{NO}_{3}{ }^{-}$remained moreor-less constant. These results are different to the results obtained by Lukes et al who observed a decrease in $\mathrm{H}_{2} \mathrm{O}_{2}$ and $\mathrm{NO}_{2}{ }^{-}$, but an increase in $\mathrm{NO}_{3}{ }^{-}$post plasma treatment. ${ }^{39)}$ This could be due to the very different plasma sources utilized by Lukes et al (air discharge plasma) compared to the He/Ar plasma jets in this study. Based on the study by Lukes et $a l^{39)}$ we note that $\mathrm{H}_{2} \mathrm{O}_{2}$ can also be formed through reactions between hydroxyl radicals also generated by the plasma jets. Also, we appreciate that changes in $\mathrm{pH}$ will influence the production of RONS post-plasma jet treatment. ${ }^{40)}$ However, further detailed experiments will need to be performed to develop a more comprehensive understanding of the liquid 
chemistry. In the future the authors will address this issue; but for the present study the general trends in RONS/ $\mathrm{O}_{2}$ (aq) delivery were more important than absolute values.

The role played by gas flow is made clearer when in Fig. $5 \mathrm{UV}-\mathrm{Vis}$ was used to monitor RONS and $\mathrm{O}_{2}(\mathrm{aq})$ in DI water for 60 min with plasma jet treatments for the first $15 \mathrm{~min}$, followed immediately after with 15 min inert gas jet treatments, and the 30 min with no applied voltage and gas flow. The trends in RONS delivery and de-oxygenation are identical to those seen in Fig. 3 and Fig. 4, with a notable exception being that the trend for $\mathrm{NO}_{3}$ delivery was similar for He and Ar plasma jets, whereas in Fig. 3 and Fig. 4 the He plasma jet delivered more $\mathrm{NO}_{3}{ }^{-}$compared to the Ar plasma jet. As mentioned before, this discrepancy is due to experimental variation and/or small errors in the automated curvefitting routine. Immediately after plasma jet treatment, between time-points 15-30 min, it can be seen that the He gas jet was more effective at de-oxygenating the DI water compared to the Ar gas jet (consistent with Fig. 4). Following treatment with the inert gas jets, and with the plasma and gas flow both off, the $\mathrm{O}_{2}(\mathrm{aq})$ concentration began to recover in the DI water; and at the 60 min time-point the $\mathrm{O}_{2}$ (aq) concentration was the same for He and Ar at $\sim 4 \mathrm{mg}$ $\mathrm{L}^{-1}$ but still approximately $50 \%$ lower compared to the original $\mathrm{O}_{2}(\mathrm{aq})$ concentration.

So far, the inert gas treatments of DI water were performed immediately after the plasma jet treatments. Therefore, the effect on the RONS and $\mathrm{O}_{2}(\mathrm{aq})$ concentrations of the gas flows only was next investigated. In Fig. $6 \mathrm{He}$ and Ar gas jets were applied for $30 \mathrm{~min}$, and UVVis was used to follow $\mathrm{O}_{2}$ (aq) recovery for the next 30 min without gas flow. As expected, in this control experiment the inert gas jets alone do not change the RONS concentrations in the DI water (consistent with Fig. 4 and Fig. 5). Again, as expected, the extent of deoxygenation seen with the He gas jet was greater than the Ar gas jet. When the inert gas jets were switched off, the $\mathrm{O}_{2}$ (aq) concentration immediately began to recover (consistent with Fig. 5). It can also be seen that the decrease and increase in the $A_{\mathrm{T}}$ follows a similar trends for the decrease and increase in $\mathrm{O}_{2}(\mathrm{aq})$. As already discussed above, this is expected because $A_{\mathrm{T}}=$ total $\mathrm{RONS}+\mathrm{O}_{2}(\mathrm{aq})$ concentrations in DI water. The decrease in $A_{\mathrm{T}}$ corresponding to the decrease in $\mathrm{O}_{2}$ (aq) was not revealed in other graphs (e.g. in Fig. 4 and Fig. 5) because of the larger intensity units required to plot $A_{\mathrm{T}}$ when RONS are generated; this is because of the lower co-efficient of absorbance of $\mathrm{O}_{2}(\mathrm{aq})$, and consequently $A_{\mathrm{T}}$ is less sensitive to changes in $\mathrm{O}_{2}(\mathrm{aq})$ when $\mathrm{H}_{2} \mathrm{O}_{2}, \mathrm{NO}_{2}{ }^{-}$and $\mathrm{NO}_{3}{ }^{-}$are present. ${ }^{9)}$ 
Reversing the order of the previous other plasma jet experiments, Ar and He gas jets were used to first de-oxygenate the DI water followed immediately by plasma jet treatments. The treatment times were: 15 min inert gas jet, 15 min plasma jet, 30 min plasma jet and gas flow off. The results are shown in Fig. 7. Although the inert gas jet reduced the original $\mathrm{O}_{2}(\mathrm{aq})$ concentration to $\sim 25 \%$ and $\sim 50 \%$ (of original levels) in DI water for He and Ar, respectively, the low $\mathrm{O}_{2}(\mathrm{aq})$ concentration did not affect the generation of RONS with the plasma jets; similar trends and concentrations were observed to those in Figs. 3-5 in the de-oxygenated DI water. But in contrast to oxygenated DI water equilibrated with ambient air, with deoxygenated DI water, both plasma jets increased the concentration of $\mathrm{O}_{2}(\mathrm{aq})$. The reason for the increase in $\mathrm{O}_{2}(\mathrm{aq})$ could possibly be due to the decay of RONS giving rise to $\mathrm{O}_{2}(\mathrm{aq})$ such as $2 \mathrm{HOO} \rightarrow \mathrm{H}_{2} \mathrm{O}_{2}+\mathrm{O}_{2}(\mathrm{aq})$ or $\mathrm{O}_{2}$ from the ambient air being entrained in the effluent of the plasma jet gas and consequently solvating into the DI water.

Having analyzed changes in the concentrations of RONS and $\mathrm{O}_{2}(\mathrm{aq})$ induced by He and Ar gas and plasma jets, the next experiments were designed to test if combinations of these treatments can be used to precisely regulate the oxygen tension and RONS concentrations in DI water. This could be useful if gas and plasma jets are utilized to regulate cell growth or function in bioreactors; e.g. decreasing the oxygen tension should decrease cell metabolism and reduce cell growth, whereas small increases in RONS concentrations can enhance cell proliferation. ${ }^{8,41)}$ For these experiments, the treatments were as follows: 9 min inert gas jet, 9 min plasma jet, 9 min inert gas and plasma jet off. The series of treatments was repeated twice and UV-Vis of the results were recorded for $60 \mathrm{~min}$. These results are shown in Fig. 8. It can be seen that the concentration of RONS and $\mathrm{O}_{2}(\mathrm{aq})$ was controlled with relatively good precision. Successive treatments with the inert gas jets resulted in well-defined decreases in $\mathrm{O}_{2}(\mathrm{aq})$ of similar magnitude, whereas successive plasma jet treatments resulted in well-defined incremental increases in the RONS concentrations.

In the scale-up to industrial applications it is also important to consider not just the control but also the efficiency of the plasma jets in the production of RONS in liquid. A protocol was previously established for assessing the efficiency of plasma jet generation of RONS in DI water. ${ }^{22)}$ In Ref. 22 it was shown that plasma jets operated with a micron-sized nozzle are more efficient at RONS generation compared to millimeter-sized nozzles, under otherwise identical conditions of operation. A second important observation in Ref. 22 was 
that subtle changes in the treatment distance over millimeter scale-lengths between the nozzle and target solution, significantly impacted on the efficiency of RONS generation; but the relationship was not linear. Herein, the same protocol described in Ref. 22 was employed in this study to compare the efficiency of RONS generation for He and Ar plasma jets with a micron-sized nozzle of $650 \mu \mathrm{m}$. These results are presented in Fig. 9 with production efficiency expressed as $\mathrm{mg} \mathrm{L}^{-1} / \mathrm{J}$ : where $\mathrm{mg}=$ quantity of RONS; $\mathrm{L}=$ volume of water; and $\mathrm{J}=$ input energy. Displaying the data in this manner it is clear that the Ar plasma jet was more efficient at producing $\mathrm{H}_{2} \mathrm{O}_{2}$, the He marginally more efficient at producing $\mathrm{NO}_{3}{ }^{-}$and both equally efficient at producing $\mathrm{NO}_{2}{ }^{-}$. Because the efficiency in the plasma jet delivery of RONS was shown to vary for different RONS and between He and Ar process gases and also the different treatment condition; e.g. He plasma jet is in contact with the water surface while Ar plasma jet is not contact with the liquid. The data show it is important to consider the production efficiency of RONS with plasma jets for larger scale industrial applications, where efficiency of RONS generation is important for maintaining lower production costs.

One aspect this study touches upon is the need to improve reliability (or predictability) in the modulation of RONS chemistry that is achieved with different plasma jets or other plasma sources, according to mode of operation or plasma set-up; e.g. the discrepancies between the results in this study to Lukes et $a l .{ }^{39)}$ Further discrepancy can be seen when comparing results herein with one of our own previous studies ${ }^{9)}$ in focusing on the plasma jet delivery particularly of $\mathrm{NO}_{2}^{-}$and $\mathrm{NO}_{3}{ }^{-}$. In order to highlight this discrepancy, a comparison is made between the He and Ar plasma jet delivery of RONS in this study (Fig. 3 above) to Fig. 9 in Ref. 9. Both studies employed a similar plasma jet set-up; in both studies $4.1 \mathrm{~mL}$ of DI water in a quartz cuvette was treated for $15 \mathrm{~min}$. Major physical (known) differences are the nozzle inner diameter, the applied voltage and frequency, treatment distances and whether or not the plasma jet plume contacted the surface of the DI water. In Ref. 9 both He and Ar plasma jets never contacted the surface of the DI water. Changing these parameters resulted in striking differences in RONS delivery between $\mathrm{He}$ and $\mathrm{Ar}$ plasma jets. Although other differences in experimental parameters cannot be discounted, we think a major contributing factor to these discrepancies is the treatment distance. This is based upon the study of Wende et al who observed that treatment distance affected the delivery of RONS from one particular plasma source but not for a second but similar plasma 
source. ${ }^{42)}$ Currently, we can only speculate on why the resultant RONS chemistry in the DI water is particularly sensitive to the treatment distance. Different treatment distances will result in different amounts of the plasma effluent mixing with air (before the gas flow reaches the liquid surface), and treatment distance will also affect water evaporation. For an example, we showed that the RONS chemistry is tunable by simply changing the treatment distance in previous work. ${ }^{43)}$ Both of these points will significantly influence the production of RONS in the gas phase, which will affect the resultant liquid chemistry. In addition, variabilities in the voltage, frequency and nozzle diameter may also influence the RONS chemistry and should not be discounted; in particular these differences can influence length of the plasma plume, which could have significant effect on RONS production (refer to discussion in following paragraph). Further fundamental research is required to establish how the plasma jet experimental parameters influences the RONS chemistry. This is not trivial especially owing to the complexity of nitrogen-oxide liquid chemistry, which is only partially understood. ${ }^{31,44)}$

To provide further insight into the mechanisms of plasma-induced RONS chemistry in solution, the temperature and $\mathrm{pH}$ of the water was measured at different time-points of $\mathrm{He}$ and Ar plasma jet treatments (Fig. 10). In Fig 10(a), it can be seen that the pH of the DI water decreased for both plasma jets with a greater decrease seen for the He plasma jet. Forty five minutes after treatments, the $\mathrm{pH}$ of the solutions increased again as the DI water began to equilibrate with the ambient air. In Fig. 10(b) it is seen that the water temperature increases with He plasma jet treatment times up to $10 \mathrm{~min}$, but begins to decrease after pro-longed treatment of $15 \mathrm{~min}$. For the Ar plasma jet, the water temperature remained relatively constant, and if anything slightly decreased, for all treatment times tested [Fig. 10(b)]. Forty five minutes after plasma treatments, the water temperature returned to approximately the original value. We propose that these differences in behavior between He and Ar plasma jets are attributed to the differences in the length of the plasma jets; $\approx 7 \mathrm{~mm}$ and $\approx 5 \mathrm{~mm}$ for the $\mathrm{He}$ and Ar plasma jet, respectively. For these plasma jets, the He plasma jet contacted the water surface for up to the first $10 \mathrm{~min}$ of treatment. But by $15 \mathrm{~min}$, plasma jet contact with the water surface was lost. This was due to the water evaporation lowering the water level in the cuvette. However, the shorter Ar plasma jet never contacted the water surface. Therefore, in the case of He, in contact mode, we propose that electrons and ions emanating 
from the plasma jet directly heat the water for up to $10 \mathrm{~min}$. At $15 \mathrm{~min}$, the water temperature decreases due to evaporative cooling. Since the Ar plasma jet was never in contact with the water surface, the water temperature remained relatively constant with a slight decrease (if anything) due to evaporation. Based upon on the literature we propose that the higher temperature seen for the He plasma jet enhances $\mathrm{NO}_{\mathrm{x}}$ reactions leading to formation of nitric acid and a lowering of the water $\mathrm{pH}^{40)}$

A number of different molecules are detected in water treated by plasma jets including short and longer lived molecules. We have established our UV-Vis method to accurately detect $\mathrm{H}_{2} \mathrm{O}_{2}, \mathrm{NO}_{2}{ }^{-}, \mathrm{NO}_{3}{ }^{-}$and $\mathrm{O}_{2}$ (aq). We do not discount the possibility that other molecules may also contribute to the UV absorbance. For example, it is important to understand the chemistry responsible for lowering the $\mathrm{pH}$ of the water during plasma jet treatment, as well the chemistry during the increase (recovery) of the $\mathrm{pH}$ after the plasma is switched off. The lowering of the $\mathrm{pH}$ solution during plasma jet treatment is likely to be due to formation of nitric acid, which we did not account for in the deconvolution of the UV absorbance spectra. However, the main decomposition product from nitric acid is $\mathrm{NO}_{3}{ }^{-45)}$ which we did measure in this study. To accurately quantify further molecules by our UV-Vis will require analysis of the reference spectrum at different wavelengths for each individual molecule at different concentrations, as detailed in a previous publication. ${ }^{43}$

In summary, this study not only demonstrated the efficacy but also highlighted the remaining challenges in using $\mathrm{He}$ and Ar plasma jets to modulate the $\mathrm{O}_{2}(\mathrm{aq})$ tension and RONS chemistry in an aqueous target. It is important to address these challenges because the development of He and Ar plasma jets to modulate RONS and oxygen tension in aqueous solutions with a high level of reproducibility, reliability and accuracy, could be exploited in a number of industrial and medical applications. This includes nanomaterials synthesis, ${ }^{46}$ ) chemical processing, ${ }^{47)}$ regulation of cell growth in bioreactors for biotechnological and pharmaceutical industries and in the production of cells for cell therapy. ${ }^{41,48-51)}$

\section{Conclusions}

Different combinations of $\mathrm{He}$ and Ar plasma and gas jet treatments were used to modulate the $\mathrm{O}_{2}(\mathrm{aq})$ tension and RONS chemistry in DI water. He and Ar plasma jets delivered oxidizing species $\left(\mathrm{H}_{2} \mathrm{O}_{2}, \mathrm{NO}_{2}^{-}\right.$and $\left.\mathrm{NO}_{3}{ }^{-}\right)$and oxygenated or de-oxygenated DI water 
depending on the $\mathrm{O}_{2}(\mathrm{aq})$ concentration at the time of treatment. He and Ar gas jets deoxygenated the DI water. Considering the electrical energy consumption, the Ar plasma jet more efficient at producing $\mathrm{H}_{2} \mathrm{O}_{2}$, and both equally efficient at producing $\mathrm{NO}_{2}{ }^{-}$. Improving our knowledge of the nitrogen-oxide liquid chemistry should assist the development of accurate, reproducible and efficient plasma jet methods for modulating RONS and $\mathrm{O}_{2}(\mathrm{aq})$ in aqueous solutions. This could significantly benefit industries that utilize large-scale chemical processing facilities or cell culture bioreactors for the manufacture of pharmaceutical products and cells for cell therapy.

\section{Acknowledgments}

JSO and MI acknowledge the MEXT-Supported Program for the Strategic Research Foundation at Private Universities (S1511021) and a project for Promoting Research Center in Meijo University. JSO acknowledges a JSPS KAKENHI Grant Number JP17K05099. EJS, S-HH, NG and RDS thank financial support from the Wound Management Innovation CRC through projects RP 2.11 and SP09-02, and the Australian Research Council through the Discovery Project DP16010498. 


\section{References}

1) E. Stoffels, Y. Sakiyama, and D. B. Graves, IEEE Trans. Plasma Sci. 36, 1441 (2008).

2) M. G. Kong, G. Kroesen, G. Morfill, T. Nosenko, T. Shimizu, J. v. Dijk, and J. L. Zimmermann, New J. Phys. 11, 115012 (2009).

3) D.-X. Liu, M.-Z. Rong, X.-H. Wang, F. Iza, M. G. Kong, and P. Bruggeman, Plasma Process. Polym. 7, 846 (2010).

4) H. Tresp, M. U. Hammer, J. Winter, K.-D. Weltmann, and S. Reuter, J. Phys. D: Appl. Phys. 46, 435401 (2013).

5) Y. Gorbanev, D. O'Connell, and V. Chechik, Chem. Eur. J. 22, 3496 (2016).

6) E. Takai, T. Kitamura, J. Kuwabara, S. Ikawa, S. Yoshizawa, K. Shiraki, H. Kawasaki, R. Arakawa, and K. Kitano, J. Phys. D: Appl. Phys. 47, 285403 (2014).

7) D. B. Graves, J. Phys. D: Appl. Phys. 45, 263001 (2012).

8) J.-S. Oh, X. Strudwick, R. D. Short, K. Ogawa, A. Hatta, H. Furuta, N. Gaur, S.-H. Hong, A. J. Cowin, H. Fukuhara, K. Inoue, M. Ito, C. Charles, R. W. Boswell, J. W. Bradley, D. B. Graves, and E. J. Szili, Appl. Phys. Lett. 109, 203701 (2016).

9) J.-S Oh, E. J. Szili, N. Gaur, S.-H. Hong, H. Furuta, H. Kurita, A. Mizuno, A. Hatta, and R.D. Short, J. Phys. D: Appl. Phys. 49, 304005 (2016).

10) C. Ross, M. Alston, J. R. Bickenbach, and N. Aykin-Burns, Exp. Dermatol. 20, 58 (2011).

11) F. Iza, G. J. Kim, S. M. Lee, J. K. Lee, J. L. Walsh, Y. T. Zhang, and M. G. Kong, Plasma Process. Polym. 5, 322 (2008).

12) S. Reuter, H. Tresp, K. Wende, M. U. Hammer, J. Winter, K. Masur, A. Schmidt-Bleker, and K. Weltmann, IEEE Trans. Plasma Sci. 40, 2986 (2012).

13) J. Winter, K. Wende, K. Masur, S. Iseni, M. Dünnbier, M. U. Hammer, H. Tresp, K.-D. Weltmann, and S. Reuter, J. Phys. D: Appl. Phys. 46, 295401 (2013).

14) H. Tresp, M. U. Hammer, K.-D. Weltmann, and S. Reuter, Plasma Med. 3, 45 (2013).

15) A. N. Seth, T. Wei, J. Eric, and J. K. Mark, J. Phys. D: Appl. Phys. 47, 475203 (2014).

16) A. Schutze, J. Y. Jeong, S. E. Babayan, J. Park, G. S. Selwyn, and R. F. Hicks, IEEE Trans. Plasma Sci. 26, 1685 (1998).

17) X.-J. Shao, N. Jiang, G.-J. Zhang, and Z.-x. Cao, Appl. Phys. Lett. 101, 253509 (2012).

18) S. Hofmann, A. F. H. v. Gessel, T. Verreycken, and P. Bruggeman, Plasma Sources Sci. Technol. 20, 065010 (2011). 
19) L. Qing, H. Takana, P. Yi-Kang, and H. Nishiyama, IEEE Trans. Plasma Sci. 42, 2360 (2014).

20) K. Tachibana and H. Motomura, Eur. Phys. J. Appl. Phys. 71, 20802 (2015).

21) J.-S. Oh, H. Yajima, K. Hashida, T. Ono, T. Ishijima, I. Serizawa, H. Furuta, and A. Hatta, J. Photopolym. Sci. Technol. 29, 427 (2016).

22) J.-S. Oh, M. Kakuta, H. Furtuta, H. Akatsuka, and A. Hatta, Jpn. J. Appl. Phys. 55, 06HD01 (2016).

23) J.-S. Oh, E. J. Szili, S. Ito, S.-H. Hong, N. Gaur, H. Furuta, R. D. Short, and A. Hatta, Plasma Med. 5, 125 (2015).

24) J.-S. Oh, E. J. Szili, N. Gaur, S.-H. Hong, H. Furuta, R. D. Short, and A. Hatta, J. Photopolym. Sci. Technol. 28, 439 (2015).

25) E. J. Szili, J.-S. Oh, S.-H. Hong, A. Hatta, and R. D. Short, J. Phys. D: Appl. Phys. 48, $202001(2015)$.

26) N. Gaur, E. J. Szili, J.-S. Oh, S.-H. Hong, A. Michelmore, D. B. Graves, A. Hatta, and R. D. Short, Appl. Phys. Lett. 107, 103703 (2015).

27) M. Naïtali, G. Kamgang-Youbi, J.-M. Herry, M.-N. Bellon-Fontaine, and J.-L. Brisset, Appl. Environ. Microbiol. 76, 7662 (2010).

28) U. K. Ercan, H. Wang, H. Ji, G. Fridman, A. D. Brooks, and S. G. Joshi, Plasma Process. Polym. 10, 544 (2013).

29) J. Julák, V. Scholtz, S. Kotúčová, and O. Janoušková, Physica Medica, 28, 230 (2012).

30) K. Oehmigen, M. Hähnel, R. Brandenburg, C. Wilke, K. D. Weltmann, and T. von Woedtke, Plasma Process. Polym. 7, 250 (2010).

31) M. J. Traylor, M. J. Pavlovich, S. Karim, P. Hait, Y. Sakiyama, D. S. Clark, and D. B. Graves, J. Phys. D: Appl. Phys. 44, 472001 (2011).

32) Y. Ito, K. Urabe, N. Takano, K. Tachibana, Appl. Phys. Express 1, 067009 (2008).

33) D. J. Jin, H. S. Uhm, and G. Cho, Phys. Plasmas 20, 083513 (2013).

34) J.-S. Oh, O. T. Olabanji, C. Hale, R. Mariani, K. Kontis, and J. W. Bradley, J. Phys. D: Appl. Phys. 44, 155206 (2011).

35) C. Chen, D. X. Liu, Z. C. Liu, A. J. Yang, H. L. Chen, G. Shama, and M. G. Kong, Plasma Chem. Plasma Process. 34, 403 (2014).

36) W. Tian and M. J. Kushner, J. Phys. D: Appl. Phys. 47, 165201 (2014). 
37) M. E. Rollie, G. Patonay, and I. M. Warner, Ind. Eng. Chem. Res. 26, 1 (1987).

38) P. J. Bruggeman, M. J. Kushner, B. R. Locke, J. G. E. Gardeniers, W. G. Graham, D. B. Graves, R. C. H. M. Hofman-Caris, D. Maric, J. P. Reid, E. Ceriani, D. F. Rivas, J. E. Foster, S. C. Garrick, Y. Gorbanev, S. Hamaguchi, F. Iza, H. Jablonowski, E. Klimova, J. Kolb, F. Krcma, P. Lukes, Z. Machala, I. Marinov, D. Mariotti, S. M. Thagard, D. Minakata, E. C. Neyts, J. Pawlat, Z. L. Petrovic, R. Pflieger, S. Reuter, D. C. Schram, S. Schröter, M. Shiraiwa, B. Tarabová, P. A. Tsai, J. R. R. Verlet, T. v. Woedtke, K. R. Wilson, K. Yasui, and G. Zvereva, Plasma Sources Sci. Technol. 25, 053002 (2016).

39) P. Lukes, E. Dolezalova, I. Sisrova, and M. Clupek, Plasma Sources Sci. Technol. 23, 015019 (2014).

40) R. Laurita, D. Barbieri, M. Gherardi, V. Colombo, and P. Lukes, Clin. Plasma Med. 3, 53 (2015).

41) E. J. Szili, F. J. Harding, S.-H. Hong, F. Herrmann, N. H. Voelcker, and R. D. Short, J. Phys. D: Appl. Phys. 48, 495401 (2015).

42) K. Wende, P. Williams, J. Dalluge, W. V. Gaens, H. Aboubakr, J. Bischof, T. von Woedtke, S. M. Goyal, K.-D. Weltmann, A. Bogaerts, K. Masur, and P. J. Bruggeman, Biointerphases 10, 029518 (2015).

43) J.-S. Oh, E. J. Szili, K. Ogawa, R. D. Short, M. Ito, H. Furuta, and A. Hatta, Jpn. J. Appl. Phys. 57, 0102B9 (2018).

44) S. Goldstein, J. Lind, and G. Merényi, Chem. Rev. 105, 2457 (2005).

45) Y. Nakashima, S. Ikawa, A. Tani, and K. Kitano, J. Chromatogr. A 1431, 89 (2016).

46) D. Mariotti and R. M. Sankaran, J. Phys. D: Appl. Phys. 43, 323001 (2010).

47) B. Eliasson and U. Kogelschatz, IEEE Trans. Plasma Sci. 19, 1063 (1991).

48) E. J. Szili, H. Thissen, J. P. Hayes, and N. Voelcker, Biosens. Bioelectron. 19, 1395 (2004).

49) L. K. Branski, G. G. Gauglitz, D. N. Herndon, and M. G. Jeschke, Burns 35, 171 (2009).

50) M. Butler, Appl. Microbiol. Biotechnol. 68, 283 (2005).

51) D. R. Gray, S. Chen, W. Howarth, D. Inlow, and B. L. Maiorella, Cytotechnol. 22, 65 (1996). 


\section{Figures and Figure Captions}

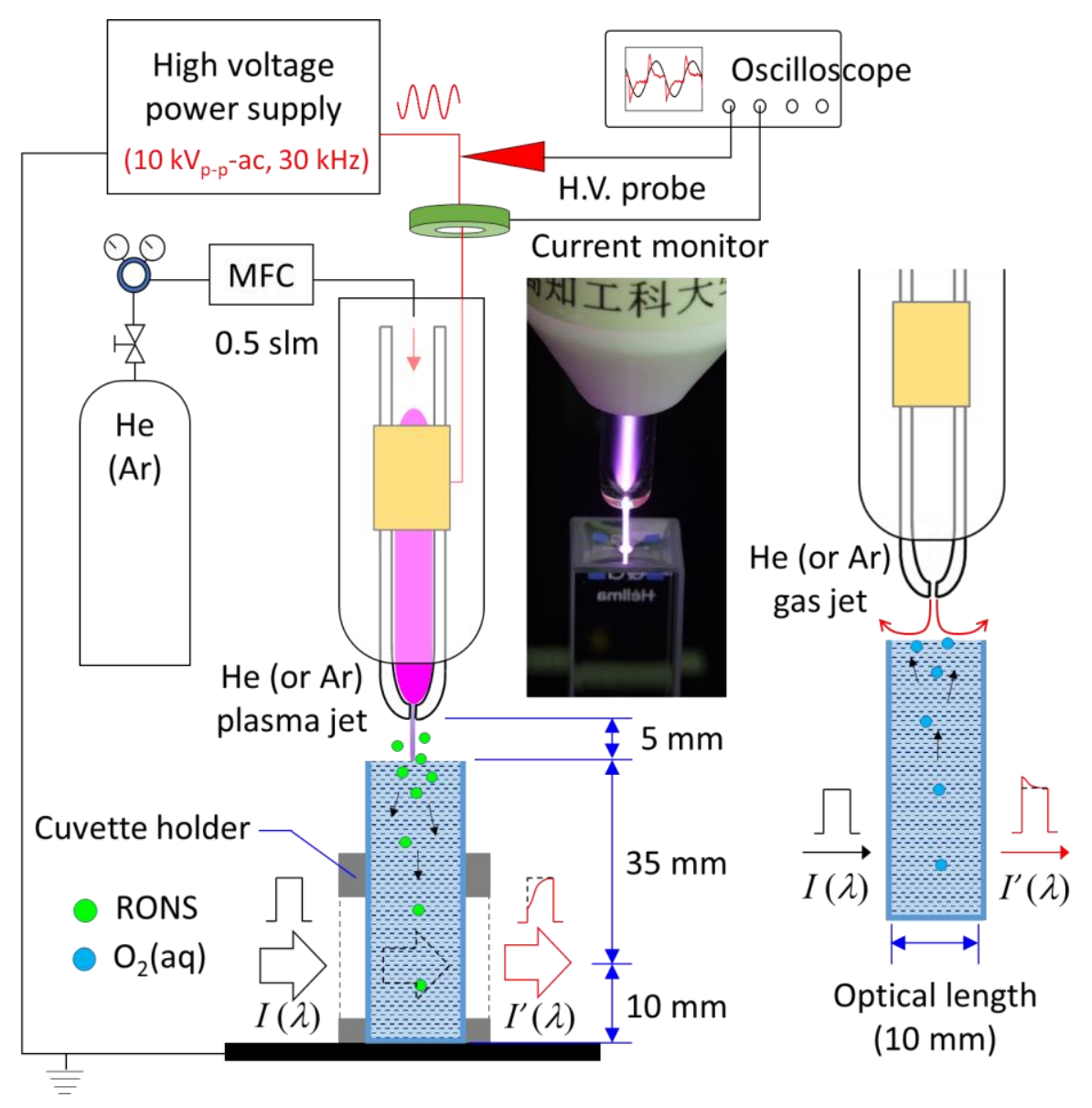

Fig. 1. (Color online) Experimental set-up where UV-Vis spectroscopy is used to monitor real-time changes in RONS and $\mathrm{O}_{2}(\mathrm{aq})$ during $\mathrm{He}$ and Ar plasma and gas jet treatment of DI water. 


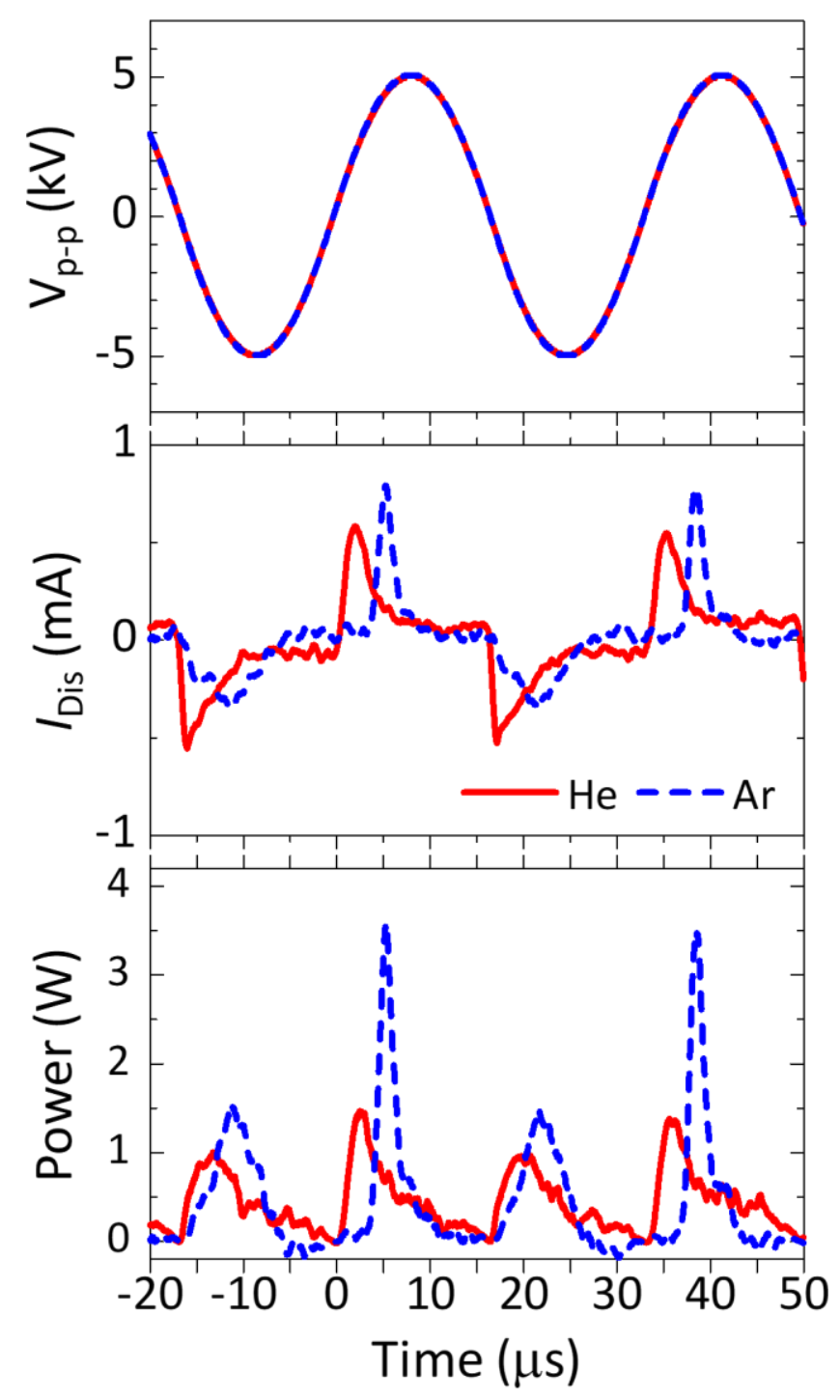

Fig. 2. (Color online) Electrical characteristics of the He and Ar plasma jets. From top-tobottom, the plots show (top graph) the peak-to-peak applied voltage waveform at $10 \mathrm{kV}_{\mathrm{p}-\mathrm{p}}$ with a frequency of $30 \mathrm{kHz}$, (middle graph) discharge current ( $\left.I_{\text {Dis }}\right)$, and (bottom graph) the input power of the discharge. The red solid lines and blue dashed lines are for the He and Ar plasma jets, respectively (as indicated in legend on middle graph). 

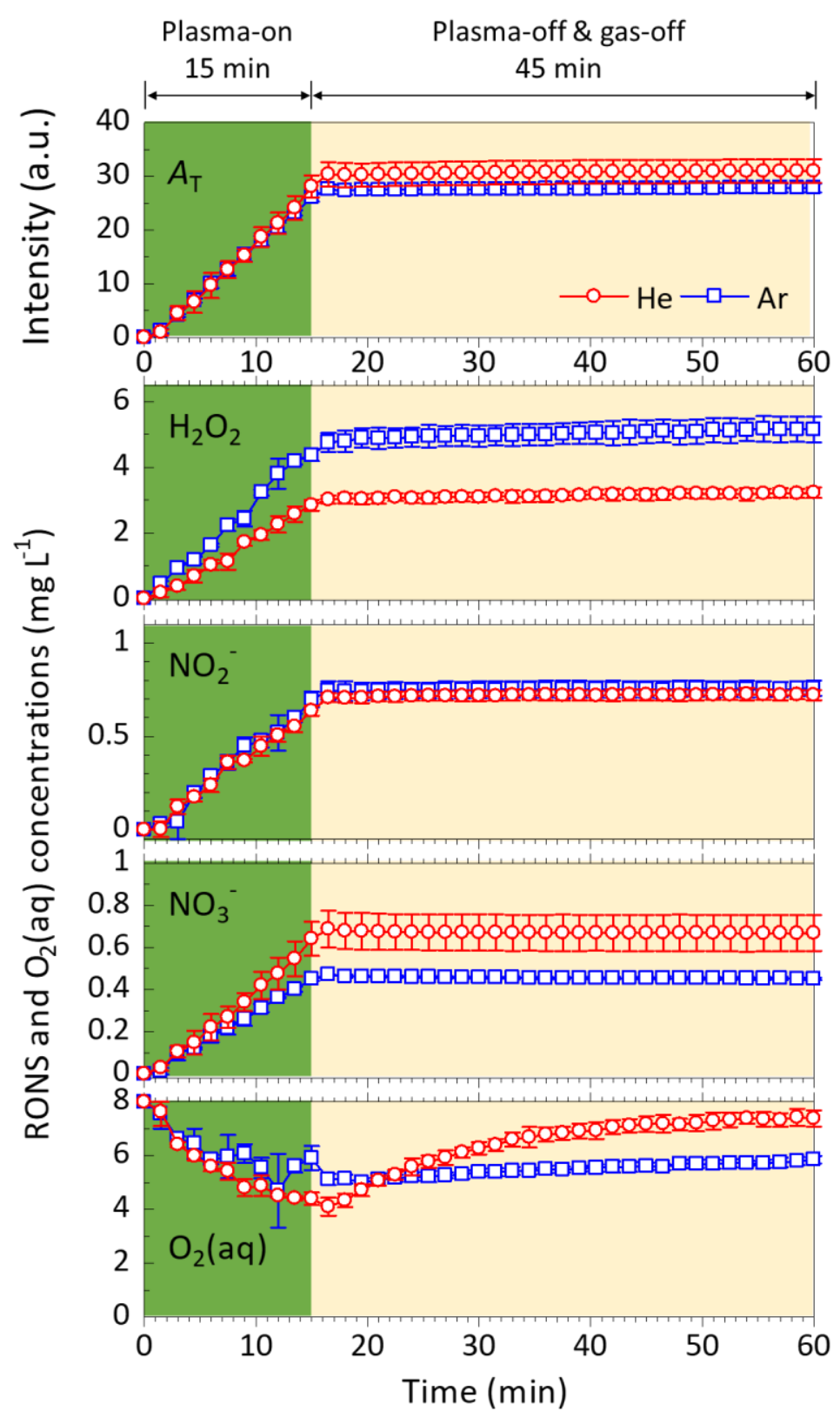

Fig. 3. (Color online) Time-dependent change in the $A_{\mathrm{T}}$ and concentrations of $\mathrm{H}_{2} \mathrm{O}_{2}, \mathrm{NO}_{2}{ }^{-}$, $\mathrm{NO}_{3}{ }^{-}$, and $\mathrm{O}_{2}(\mathrm{aq})$ in DI water during $\mathrm{He}$ and Ar plasma jet treatments, as measured by UVVis. The treatment time was $15 \mathrm{~min}$ (shaded green) after which the plasma jets and the gas flows were switched off (shaded beige). The red circles and blue squares represent the data for the He and Ar plasma jets, respectively (as indicated in legend on top graph). $A_{\mathrm{T}}=$ sum of absorption signal intensity in the scanning wavelength range between 190-340 $\mathrm{nm}$. 

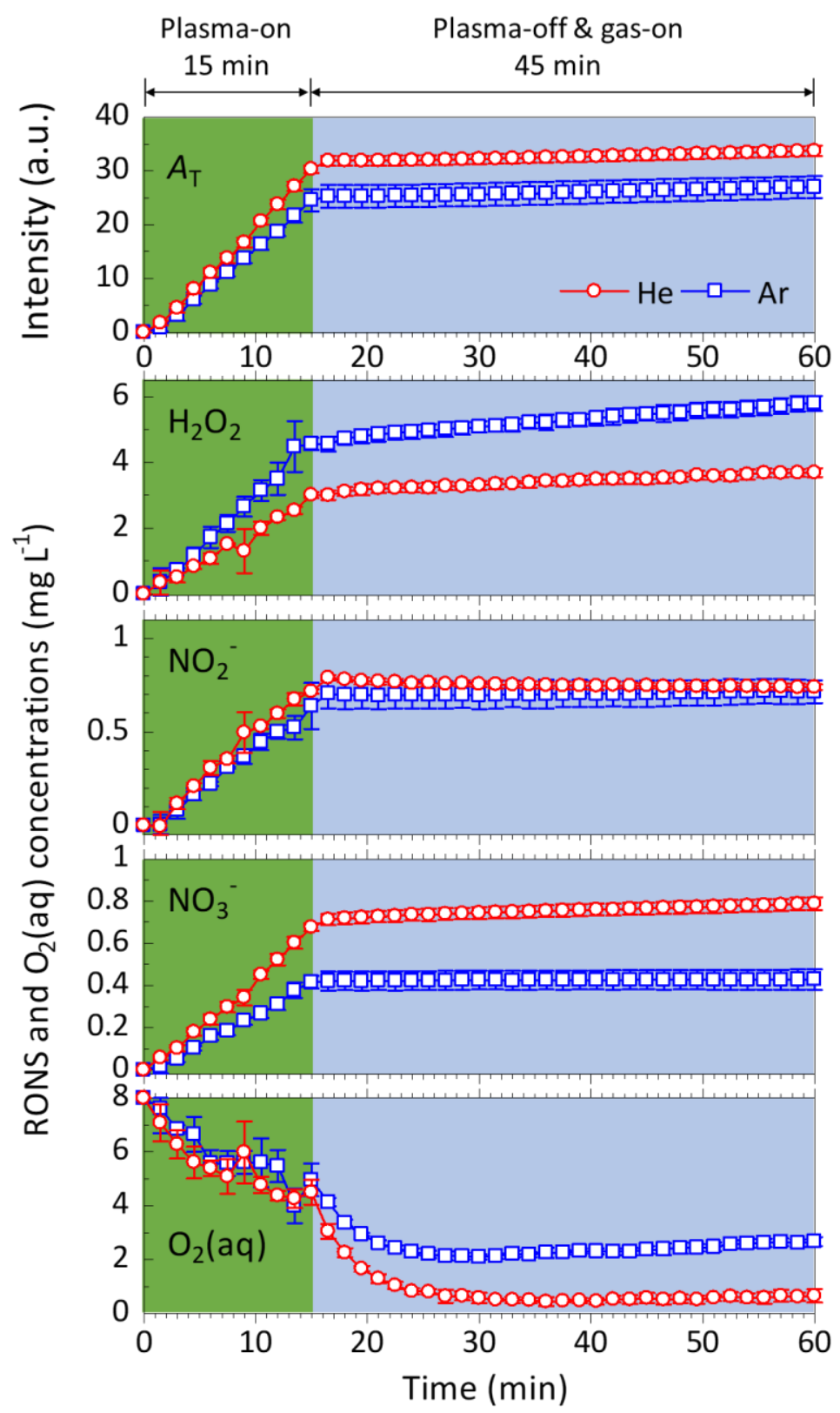

Fig. 4. (Color online) Time-dependent change in the $A_{\mathrm{T}}$ and concentrations of $\mathrm{H}_{2} \mathrm{O}_{2}, \mathrm{NO}_{2}$, $\mathrm{NO}_{3}{ }^{-}$, and $\mathrm{O}_{2}(\mathrm{aq})$ in DI water during $\mathrm{He}$ and Ar plasma jet and gas jet treatments, as measured by UV-Vis. The plasma jet treatment time was $15 \mathrm{~min}$ (shaded green), followed immediately by 45 min of inert gas jet treatment (shaded blue). The red circles and blue squares represent the data for the He and Ar plasma or gas jets, respectively (as indicated in legend on top graph). $A_{\mathrm{T}}=$ sum of absorption signal intensity in the scanning wavelength range between 190-340 nm. 


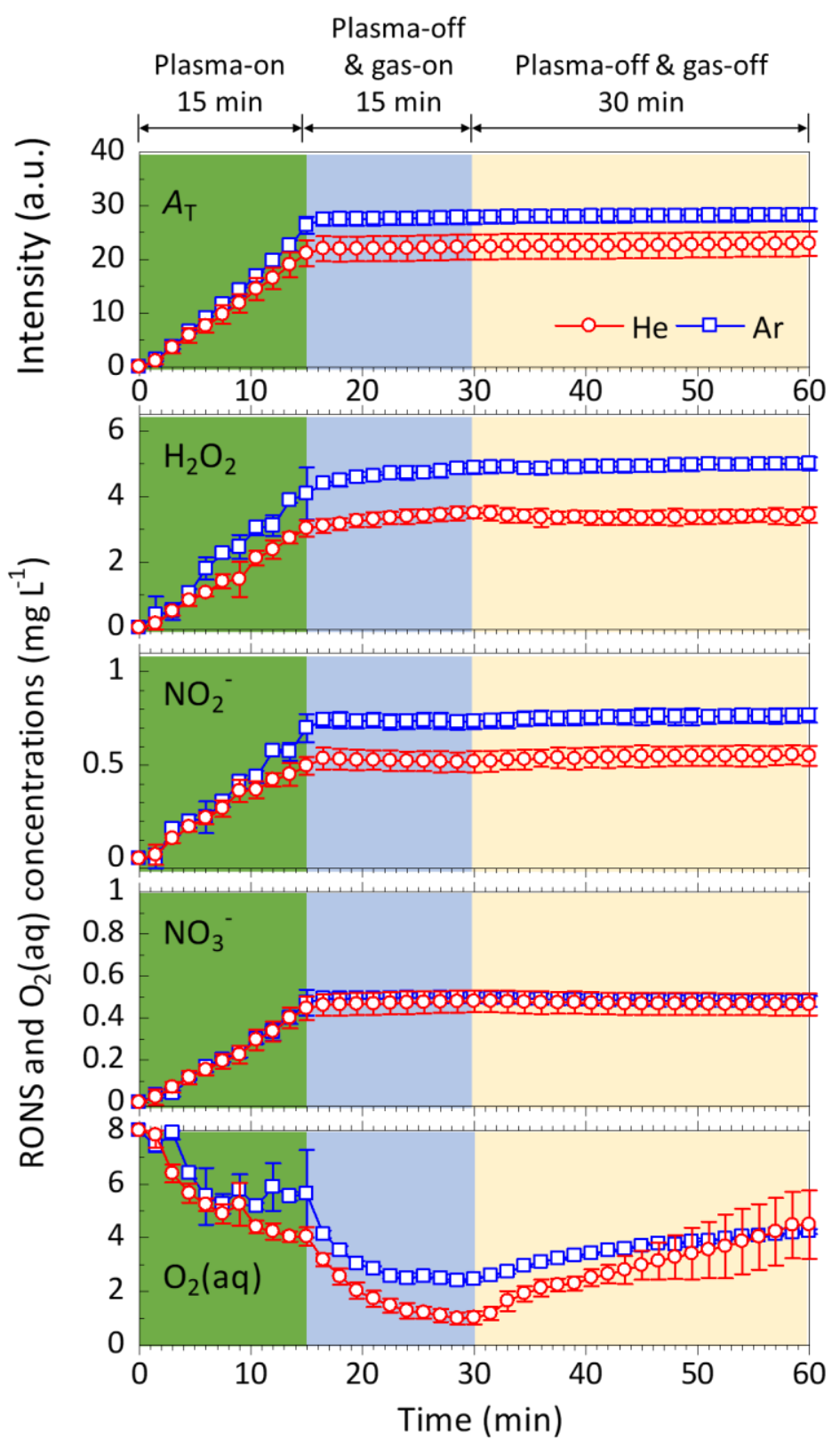

Fig. 5. (Color online) Time-dependent change in the $A_{\mathrm{T}}$ and concentrations of $\mathrm{H}_{2} \mathrm{O}_{2}, \mathrm{NO}_{2}$, $\mathrm{NO}_{3}{ }^{-}$, and $\mathrm{O}_{2}(\mathrm{aq})$ in DI water during $\mathrm{He}$ and Ar plasma jet and gas jet treatments, as measured by UV-Vis. The plasma jet treatment time was $15 \mathrm{~min}$ (shaded green), followed immediately after with 15 min of inert gas jet treatment (shaded blue), and 30 min with the plasma jet and gas flow off (shaded beige). The red circles and blue squares represent the data for the $\mathrm{He}$ and Ar plasma or gas jets, respectively (as indicated in legend on top graph). $A_{\mathrm{T}}=$ sum of absorption signal intensity in the scanning wavelength range between 190-340 nm. 

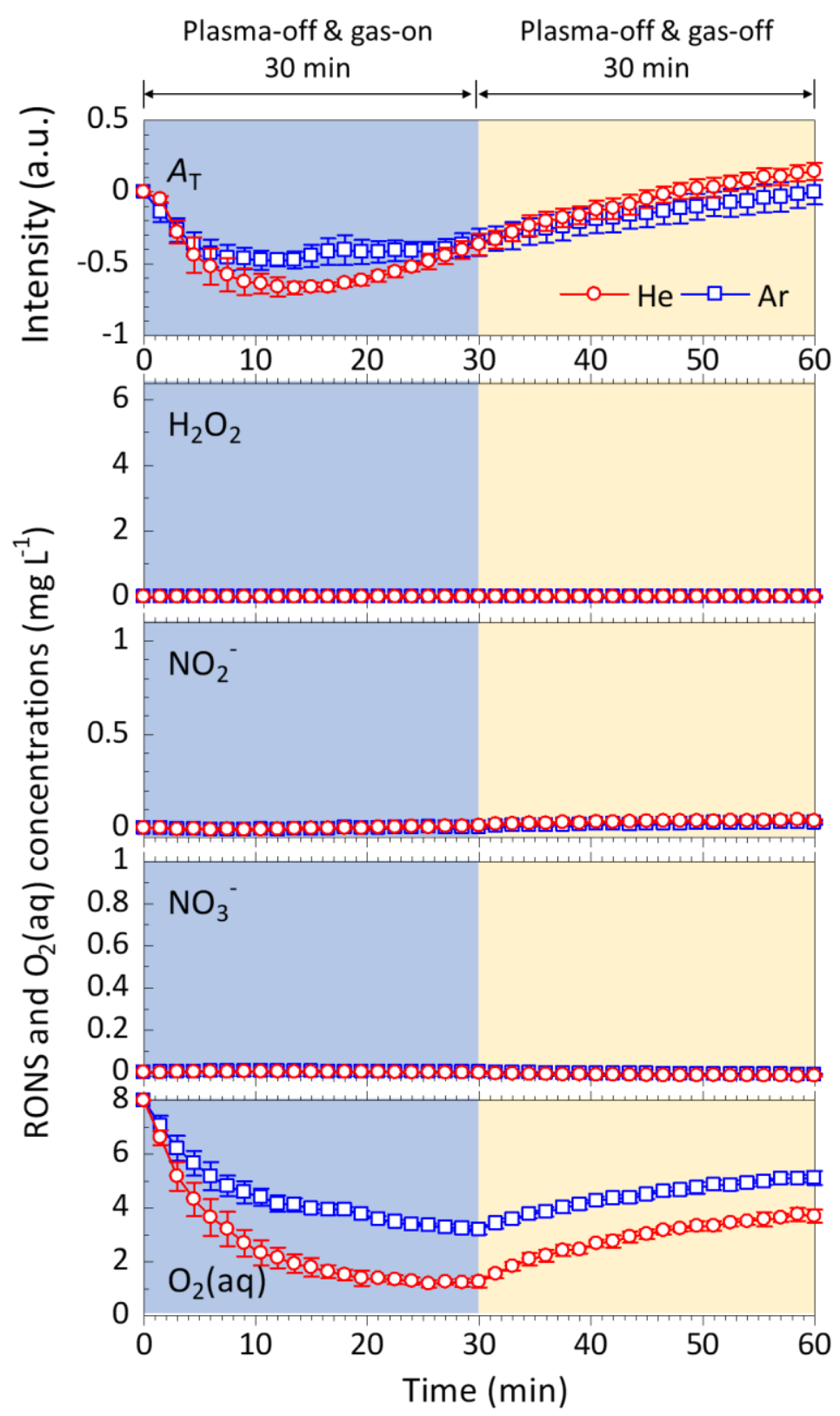

Fig. 6. (Color online) Time-dependent change in the $A_{\mathrm{T}}$ and concentrations of $\mathrm{H}_{2} \mathrm{O}_{2}, \mathrm{NO}_{2}$, $\mathrm{NO}_{3}$, and $\mathrm{O}_{2}$ (aq) in DI water during $\mathrm{He}$ and $\mathrm{Ar}$ gas jet, as measured by UV-Vis. The treatment time was 30 min (shaded blue), and 30 min with the gas flow off (shaded beige). The red circles and blue squares represent the data for the He and Ar gas jets, respectively (as indicated in legend on top graph). $A_{\mathrm{T}}=$ sum of absorption signal intensity in the scanning wavelength range between 190-340 $\mathrm{nm}$. 


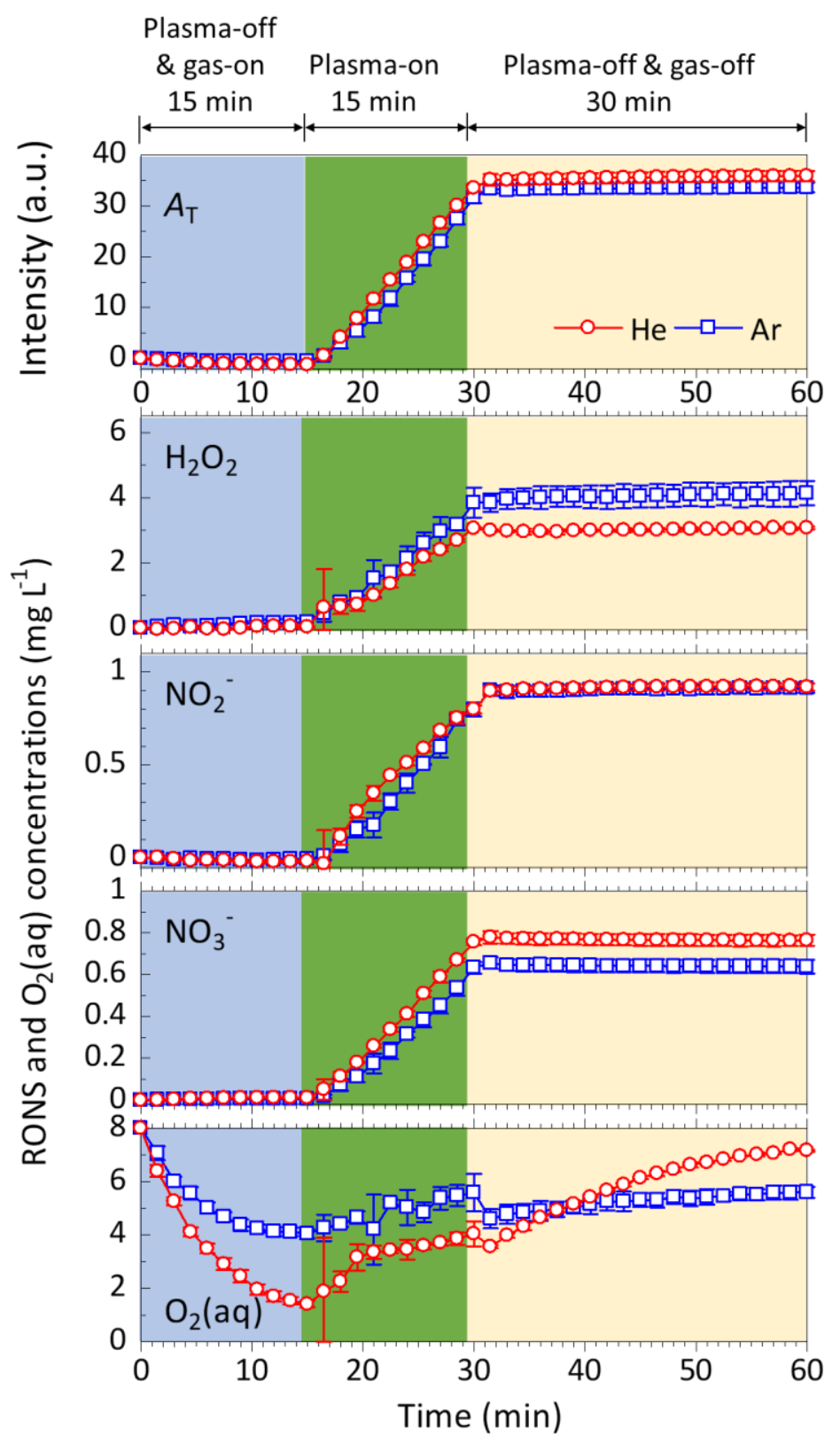

Fig. 7. (Color online) Time-dependent change in the $A_{\mathrm{T}}$ and concentrations of $\mathrm{H}_{2} \mathrm{O}_{2}, \mathrm{NO}_{2}{ }^{-}$, $\mathrm{NO}_{3}{ }^{-}$, and $\mathrm{O}_{2}$ (aq) in DI water during $\mathrm{He}$ and Ar gas jet and plasma jet treatments, as measured by UV-Vis. The gas jet treatment time was $15 \mathrm{~min}$ (shaded blue), followed immediately after with 15 min of plasma jet treatment (shaded green), and 30 min with the plasma jet and gas flow off (shaded beige). The red circles and blue squares represent the data for the He and Ar gas and plasma jets, respectively (as indicated in legend on top graph). $A_{\mathrm{T}}=$ sum of absorption signal intensity in the scanning wavelength range between 190-340 $\mathrm{nm}$. 


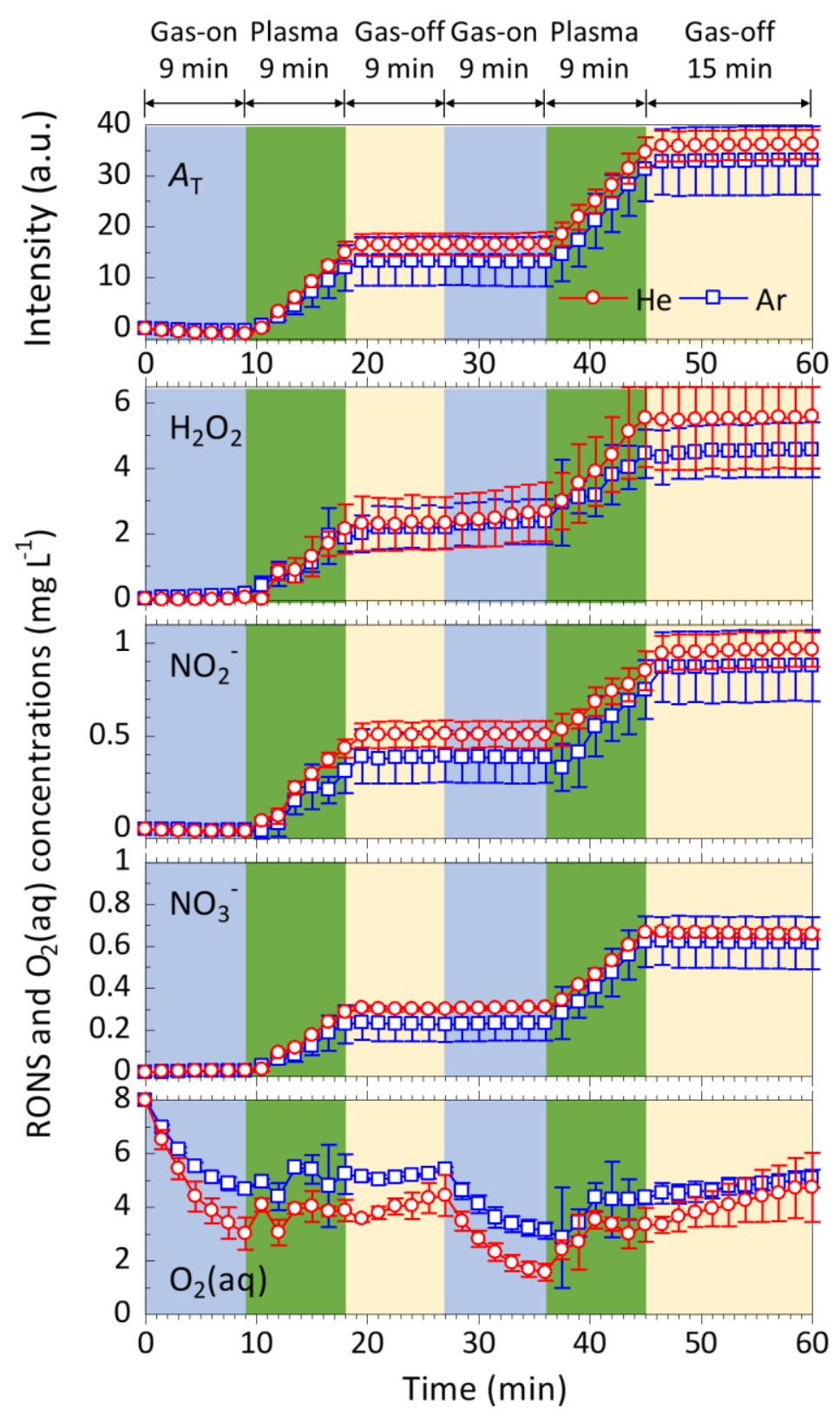

Fig. 8. (Color online) Time-dependent change in the $A_{\mathrm{T}}$ and concentrations of $\mathrm{H}_{2} \mathrm{O}_{2}, \mathrm{NO}_{2}$, $\mathrm{NO}_{3}$, and $\mathrm{O}_{2}(\mathrm{aq})$ in DI water during repetitive $\mathrm{He}$ and $\mathrm{Ar}$ gas jet and plasma jet treatments, as measured by UV-Vis. The gas jet treatment time was 9 min (shaded blue), followed immediately after with 9 min of plasma jet treatment (shaded green), and 9 min with the plasma jet and gas flow off (shaded beige). The treatment cycle was repeated twice with UVVis recorded to the $60 \mathrm{~min}$ time-point. The red circles and blue squares represent the data for the $\mathrm{He}$ and $\mathrm{Ar}$ gas and plasma jets, respectively (as indicated in legend on top graph). $A_{\mathrm{T}}=$ sum of absorption signal intensity in the scanning wavelength range between 190-340 $\mathrm{nm}$. 


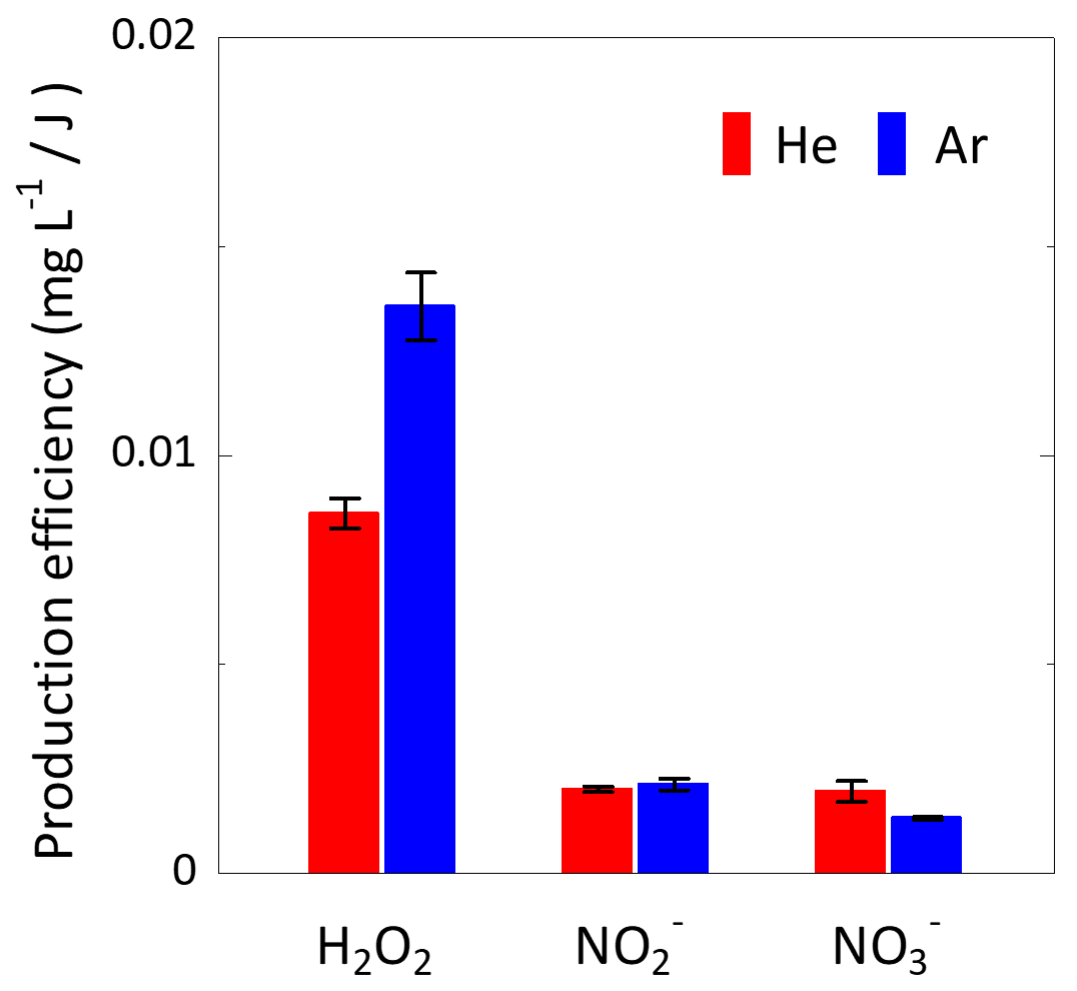

Fig. 9. (Color online) Production efficiency of He and Ar plasma jets for the delivery of $\mathrm{H}_{2} \mathrm{O}_{2}, \mathrm{NO}_{2}$, and $\mathrm{NO}_{3}{ }^{-}$into DI water. Efficiency of RONS production was measured after 15 min plasma jet treatment of $4.1 \mathrm{~mL}$ DI water as per the experimental set-up in Fig. 1. The red and blue bars represent the data for the $\mathrm{He}$ and Ar plasma jets, respectively (as indicated in the legend). 

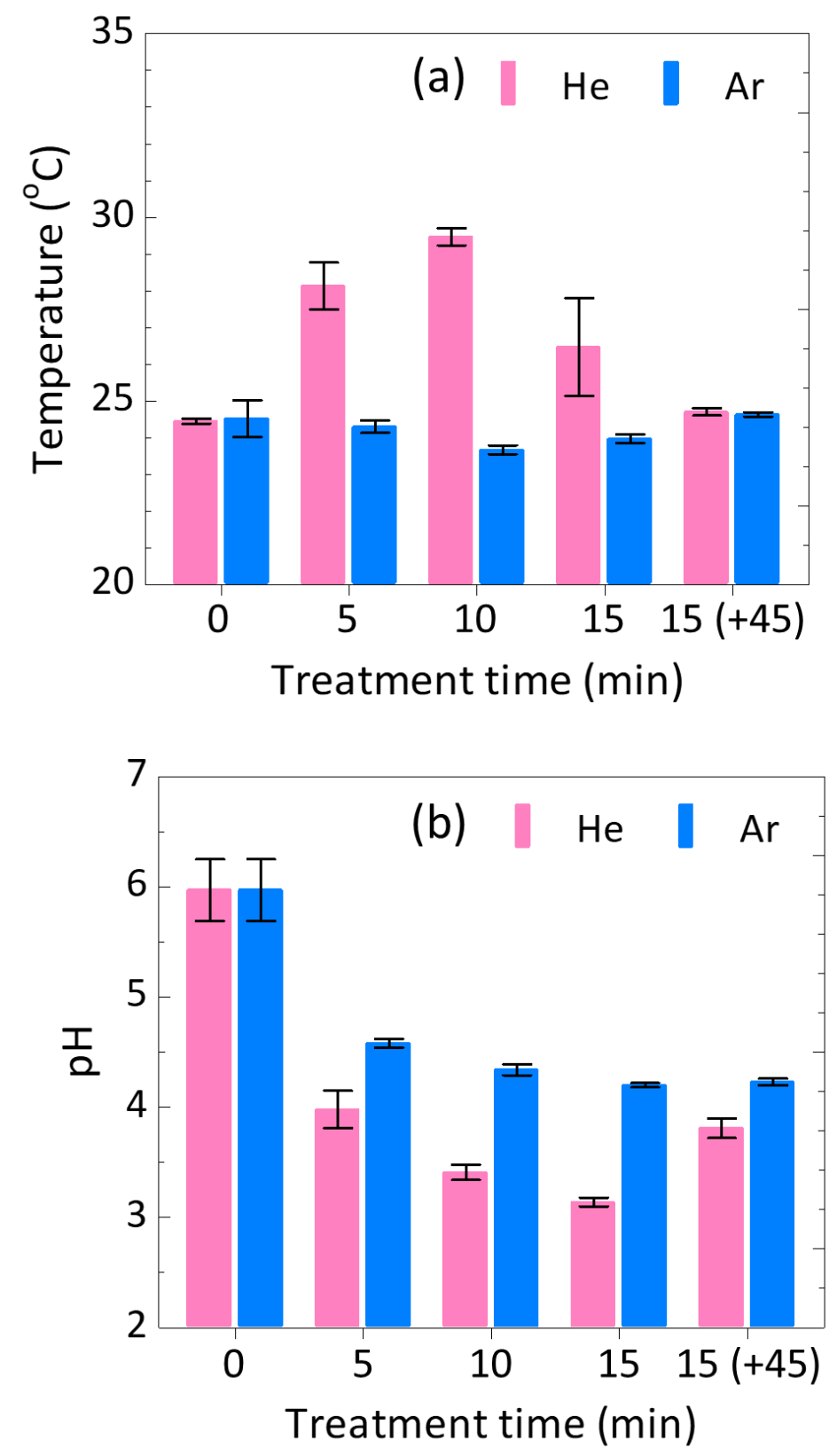

Fig. 10. (Color online) Time-dependent change in the (a) $\mathrm{pH}$ and (b) temperature of the DI water after different times of $\mathrm{He}$ and Ar plasma jet treatments. On the far right side, 15(+45) refers to measurements taken 45 min after a 15 min plasma jet treatment. The He plasma jet contacted the water up to $10 \mathrm{~min}$ but was not in contact at $15 \mathrm{~min}$. The Ar plasma jet never contacted the water surface. 